\title{
Research findings and decision making: the case of renewable energy
}

\author{
Valentina Castellani ${ }^{1 *}$, Andrea Piazzalunga $^{1}$ and Serenella Sala ${ }^{2}$
}

\begin{abstract}
Background: Energy policies from local to global scale are increasingly questioned in terms of sustainability. Evidence- and science-based decision making in this field needs a robust and transparent integrated assessment of policy options. Nevertheless, scientific findings do not lead straight to political conclusions, and the relationship between science and decision making is a debated issue. The article discusses the main barriers to effective interaction and communication between scientific enquiry and decision making and proposes some effective ways to overcome these barriers, starting from experiences in the biomass energy sector.

Results: The article discusses the case of wood fuel, focusing on one of the European hot spots for air pollution, namely the Po Valley in Northern Italy. It proves to be an interesting case, especially because of the ambiguity between the positive and the negative aspects of wood burning, which, if not adequately integrated by information about the specific conditions that influence pollution levels, can lead to opposite political decisions about the use of wood in local energy plans.

Conclusions: Starting from scientific findings, it is possible to derive guidelines about the best practices to adopt in order to reduce environmental impacts along the whole wood fuel chain. In this regard, associations of producers and of consumers and other existing networks (e.g., forestry consortia) can be very useful, either as a source of information not published in the scientific literature and as intermediaries for translating the knowledge into a more usable format and to convey information to the final targets identified (e.g., policy makers, firms, and final users).
\end{abstract}

Keywords: Science-policy interface; Integrated assessment; Sustainability assessment; Renewable energy; Wood-fuel chains; Wood burning

\section{Background}

Energy policies from local to global scale are increasingly questioned in terms of sustainability. Either from the perspective of socioeconomic sustainability of the dependence from fossil resources that are crucial for the economy and constantly depleted or from the environmental sustainability perspective related to emissions, security etc., the concern is not only limited to fossilbased energy production, but also to renewable energy, especially when seeking for the best trade-off in terms of reducing impact while ensuring economic and social feasibility of the proposed options. Evidence- and science-

\footnotetext{
* Correspondence: valentina.castellani1@unimib.it

${ }^{1}$ Department of Earth and Environmental Science, University of MilanoBicocca, Piazza della Scienza 1, Milan 20126, Italy

Full list of author information is available at the end of the article
}

based decision making needs a robust and transparent integrated assessment of policy options.

Concerning science-stakeholder-policy interface, the key stepping stone has been the Aarhus Convention. In 1998, the UNECE Convention on Access to Information, Public Participation in Decision-making and Access to Justice in Environmental Matters, known as the Aarhus Convention [1], entered into force, granting the public their rights to access environmental information. Nonetheless, the implementation of the convention [2] and the capability of scientific community to interact in a trans-disciplinary setting [3] with other stakeholders (being citizens, local authorities, or policy makers) are still at their initial stages of development.

In fact, even if stakeholder participation and informed decision making are advocated by many policies (e.g., Strategic Environmental Assessment directive and Environmental

\section{里}


Impact Assessment directive), the current level of deep interaction between the scientific community and the broader audience (including policy makers) is limited.

The present study aims at depicting the context and the need of strengthening science-stakeholder-policy interface to achieve sustainability goals, acknowledging the need of transparent communication, of translating scientific results in comprehensible knowledge for a broader audience and in operational options for decision makers.

After a review of the 'State of the art in the relationship between science and decision making' section and the 'Main barriers in the relationship between science and decision making' section, we discuss the case of a renewable energy source, namely wood fuel, in the 'Results and discussion' section. We take this as an example because wood as energy source is highly debated for its possible benefits and drawbacks in term of environmental sustainability, which strongly depend on the way in which wood is managed along the whole supply chain. 'The Po Valley hot spot in Europe' subsection illustrates the case study in Po Valley, in Northern Italy, taken as reference because it is one of the air pollution hot spots in Europe; in the 'Guidelines for wood burning arising from research findings' subsection, we present the main guidelines that can be derived from current research findings in order to promote an environmentally sustainable use of wood fuel. Finally, the 'Conclusions' section draws some conclusions about the means to overcome the identified barriers, upscaling the findings in renewable energy sector to a more wide and general level.

\section{State of the art in the relationship between science and decision making}

The priorities for the sustainability policy agenda have evolved since the Rio'92 Earth Summit both in regard to the main themes and to the strategies to be adopted [4]. During the 1990s, sustainability policies were more concerned about the environmental impacts from the production side (e.g., air and water pollution, environmental hazards from chemicals), while, since the Johannesburg meeting in 2002, more attention was paid also to the consumption side and the consumers' choices and lifestyles [5,6]. In recent years, the attention of citizens on the issues of sustainability, environmental impacts, and sustainable behavior has grown considerably [7]. In parallel, the demand for scientifically sound and transparent information upon which to base consumption choices and behaviors is growing among citizens. Now, as we are in the Rio+20 era, there is an emerging demand of concrete actions [8] and stronger implementation of the existing policies and international resolutions and for concrete actions to meet the targets set in the previous year [9].
This point of view requires informed decision making to ensure effectiveness of the policies and actions undertaken. At the same time, informed decision making calls for clear and understandable information from science ('usable knowledge', [10]), based on a deep understanding of the complexity and the cause-effect chains which rule the system under study (i.e., the system where the actions should take place).

The European Environmental Agency in 1999 proposed the Driving Forces-Pressures-State-Impacts-Responses (DPSIR) framework (Figure 1) as a conceptual model to be used in the assessment and management of environmental problems. 'According to this systems analysis view, social and economic developments exert Pressure on the environment and, as a consequence, the State of the environment changes, such as the provision of adequate conditions for health, resources availability and biodiversity. Finally, this leads to Impacts on human health, ecosystems and materials that may elicit a societal Response that feeds back on the Driving forces, or on the state or impacts directly, through adaptation or curative action' [11]. Following this framework, decision makers should be able to take informed decisions (responses) based on the knowledge of the cause-effect mechanisms provided by science.

Nevertheless, scientific findings do not lead straight to political conclusions, and the relationship between science and decision making is a debated issue, which has been extensively discussed in many disciplines.

Philosophies of science and environmental sociology (such as those of Robert Merton and Karl Popper) have long debated the role of science in society and in decisionmaking processes, firstly posing high confidence in science as the source of every solution for improving human conditions and later on questioning the reliability of scientific results and raising scepticism about science and scientists. Other studies relate to the discussion about 'technological optimism', which emphasizes the role of technology and proposes technological efficiency as the solution for improving sustainability $[12,13]$, and 'science scepticism',

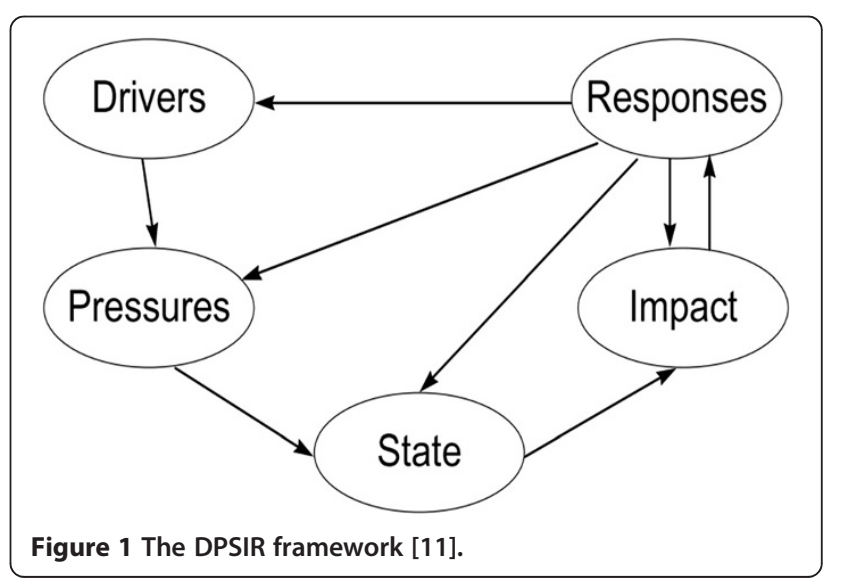


which poses the blame for environmental problems to the scientific approach and its being too narrowed about technological improvements without considering the human dimension of society [14-16]. The debate is still ongoing, as demonstrated by the essay 'We cannot live by scepticism alone' published in 2009 by Collins [17] and the related letters published on the following issue of Nature (see, for instance, $[18,19])$. Recent studies advocate also a civil role by scientists in democracy: Dean [20] states that scientists should understand that trying to interpret the scientific results and to communicate them to the politicians and to the public is not a waste of time but a valuable public engagement.

Others discuss the need to network-base the approach to decision making: Biermann and colleagues [21] propose a framework for 'earth system governance', i.e., the interrelated and increasingly integrated system of formal and informal rules, rule-making systems, and actor-networks at all levels of human society (from local to global) that are set up to steer societies towards preventing, mitigating, and adapting to global and local environmental change (p. 279).

Indeed, policy making cannot be based only on factual and objective information but should consider also power, interests, values, and norms [22,23]. Therefore a bidirectional relationship between science and policy is needed and should be based on the exchange of understandable information. The mutual exchange at the interface between science and policy has been interestingly modeled by Turnhout and colleagues [24] as a fuzzy area where these two domains overlap: scientific knowledge is translated into usable knowledge for decision makers (policy makers, businesses, citizens), and policy questions are translated into research questions that drive the research to produce guidelines for solving policy problems.

However, this relationship is sometimes questioned with reference to the modalities in which it takes place. For instance, Vareman and Persson [25] discuss whether or not a functional separation of risk assessment and risk management is needed. Elements in support of the separation are the following: risk assessment is a scientific activity which should be done independently, following scientific principles and procedures, whereas risk management is a decision-making activity that necessarily involves valuedriven decisions (e.g., how to interpret the evidence coming from risk assessment and how to translate it into prevention or mitigation actions). However, authors in support of non-separation (e.g., [26]) state that it is not enough for the risk managers merely to be given the results of the risk assessment and that 'a critical understanding of tools used for estimating risks enables an understanding of the actual extent of risk that is or is not indicated by a given piece of evidence' ([26], p. 268).

These discussions highlight some common drawbacks in the relation between science and decision making. Scientific research can have a role in the promotion of more sustainable patterns of consumption and production because it can provide information aimed to raise awareness about the impacts of different behaviors and to support more sustainable choices from different kind of decision makers (e.g., policy makers, citizens, or entrepreneurs). The challenge posed to science in this context is to provide information that is effectively supporting for decision-making processes at different scales and that can be easily understood by all the stakeholders involved in the process. Therefore, the environmental scientist cannot limit its work to the definition of the problem (e.g., climate change), leaving entirely to others the task to decide on how to solve it. The solution has to be evidence based, following an environmental and socioeconomic perspective, promoting a mutual and continuous exchange both among experts from several disciplines and among experts and stakeholders $[24,27,28]$.

At present, this exchange is mostly lacking, as demonstrated by the results of a study conducted by Holmes and Clark [29] in the UK, which confirm also the results of previous study in the field of science-policy interface, referred to the whole European Union (EU) area [30,31]. Even if there is a growing number of scientists hired in governmental agency (e.g., the Environmental Protection Agency at different scales, viz. national and regional), effective communication of the research results is still problematic. The lack of communication between science, policy, and citizens can lead to non-evidence-based decision making, lack of trust, and unsustainable behavior due to low level of information and awareness.

As explained in the 'Background' section, the present paper, grounded on the previous discussion, aims to discuss the main barriers to effective interaction and communication between scientific enquiry and decision making and to propose some effective ways to overcome these barriers, starting from experiences in the biomass energy sector.

\section{Main barriers in the relationship between science and decision making}

Informed decision making should be based on a wide range of information, which should enable the decision maker to understand the problem under investigation and to choose among several alternatives of action which is the most suitable with reference to the aim of the intervention and the context in which it takes place.

If we take as an example the well-known climate change issue, we know that the directions for reducing environmental impacts of greenhouse gas (GHG) emissions for mobility should suggest preferring walking, cycling, or use of the public transport instead of private car. However, we could not compare the environmental impact, i.e., the viability of the different options, without knowing the data 
about GHG emissions from each of them and the effect of GHG emission on climate change.

In more general terms, in order to tackle an (environmental) issue and to take informed decisions, the following are needed:

- A detailed knowledge about the current state of the system under consideration.

- Information about the uncertainty related to the knowledge of that state (i.e., about the robustness of conceptual models used to study the problem and of data measured/assessed).

- Scenario analysis and identification of the main elements that can influence future state of the system under study (e.g., what makes one option more preferable than others), i.e., which are the conditions that can determine the optimal intervention in site-specific conditions [32].

Therefore, science should be able to provide all of the information to decision makers, or looking at the same problem from an opposite point of view, decision makers should be able to derive this information from the results of scientific enquiry. Nevertheless, there are some barriers that prevent this information to be effectively delivered/taken (some of which have been already described in $[28,29])$ :

1. The absence of a defined share of responsibility between who provides the information and who takes the decisions (i.e., who holds the responsibility of informed decision making, e.g., of defining the emission reduction targets and related climate and energy policies?)

2. The difficulty, experienced by scientist, to make decision makers aware about the fact that there is no optimal solution in absolute terms, but that

(a) One alternative can be better than others considering some aspects but worse than others considering other aspects (as what usually happens with the results of comparative life cycle assessment studies). It implies that decision making cannot be based only on objective data but must necessarily involve a value judgment (e. g., the choice of the most preferable alternative is made also upon weighting of the aspects which are given priority by the decision maker).

(b) Results of the evaluation of the optimal alternative can deeply depend from site-specific conditions, such as higher vulnerability of an area compared to others (e.g., Po Valley is one of the most polluted areas in Europe especially on particulate matter (PM) concentration; hence, actions that imply significant PM emission can be excluded a priori, even if they could be preferable according to other criteria.

3. The feasibility of one alternative depends not only from objective conditions, but also from subjective elements, such as its acceptability by the local stakeholders. It again implies that decision making needs to be based both on objective and subjective information and criteria.

4. The difficulty in communicating the uncertainty related to scientific results and the possibility to have opposite and coexisting scientific positions. At present, science is not anymore seen as the source of the absolute truth, and people (i.e., decision makers) are fully aware that scientific results are affected by a certain degree of uncertainty and that scientific theory could be challenged in the future due to new discoveries and results. However, how to communicate the uncertainty in a way that does not prevent decision making is still a debated issue [33]. Moreover, it is important to give decision makers the appropriate tools to understand that the existence of two opposite theories could not have the same importance in the scientific community, due to the fact that one of them may have only few supporters, whereas the other may be endorsed by the majority of scientists.

5. Usually, the information needed to take some decisions involves a wide range of knowledge; it means that multidisciplinary cooperation (e.g., between environmental and social scientists) is needed in order to improve the decision support process [34].

6. The communication between science and decision makers is not a structured activity but usually takes place only when public opinion raises some concerns about an argument or when there is a risk or an emergency to be managed. The main reasons for this are the following:

(a) Scientists and decision makers speak different languages and have different background knowledge, points of view, and priorities; these conditions hamper the possibility of an easy understanding of research results by decision makers [35].

(b) The organization of the scientific community is based on scientific publication as the main way to evaluate the research work; therefore, time spent in communication is perceived by scientists as time wasted and not useful for their career $[20,29]$.

(c) Sometimes, politicians as decision makers are not always willing to refer to scientific knowledge in their decision process.

(d)Sometimes, scientists are not able, or not used to, look at the 'big picture' and to interpret their 
results in order to give advice on their meaning in a broader perspective and their use in support of decision making.

(e) Sometimes, both scientists and politicians define research activities based on economic interests.

Therefore, scientists and decision makers should understand that it is neither possible nor useful for scientists to provide information which represents the absolute truth or which can be considered valid in any condition. The task of science is not to give final answers but to provide the tools that enable decision makers to make informed decisions, i.e., tools to analyze situations, to identify cause-effect relationships between the components of a system, and to predict the possible outcomes of feasible interventions.

Thus, the most effective way to convey scientific results into decision making should be to identify which are the critical aspects of the system under study and which are the operative solutions that can help maximize the benefits from the management of that system, i.e., defining warnings and guidelines that should be followed by decision makers at several levels in order to ensure sustainability of the entire system. Guidelines should be the result of the interpretation of data in a broader context, considering all the possible options for intervention (e.g., to tackle an environmental problem or to develop a sustainability policy) and highlighting implications and effects for all of the options considered. An example of guidelines is given in the following section, starting from the experience in the case of wood fuel chains.

Besides the stated difficulties in communication between science and policy, one possible way of success in environmental communication could be represented by the presence of those intermediaries who have relationships with key stakeholders/decision makers and are able to translate information for them so that they become understandable and usable for action [20,29]. As mentioned before, the following section discusses this approach starting from the issue of renewable energy generation from woody biomass, which can be a controversial matter of discussion in terms of decision making.

\section{Results and discussion}

\section{The case of renewable energy from woody biomass}

An interesting example of the need of a robust sciencestakeholder-policy interface is related to the use of renewable energy sources, particularly from woody biomass. Energy resources play a fundamental role in the world's future. There are many alternative renewable energy sources which can be used instead of fossil and conventional fuels. The decision as to what types of energy source should be utilized must, in each case, be made on the basis of economic, social, environmental, and safety considerations. The EU has set seven flagship initiatives of the Europe 2020 Strategy [36] to increase economic performance while reducing resource use; to promote innovation, new sources of growth, and competitiveness; to ensure the security of supply of essential resources; and to fight against climate change and limit environmental impacts of resource use. In the Biomass Action Plan [37], the European Commission states 'Energy is a key in helping Europe achieve its objectives for growth, jobs and sustainability.' Renewable energy in general and bio-based renewable in particular have a central role in this. Indeed, forests could play a key role in energy policy and in the overall bio-economy [38] because forests and other wooded land cover 178 Mha in Europe ( $42 \%$ of the European land), and their growing stock is estimated in $23 \mathrm{Mmc}$ in 2005 . Moreover, $60 \%$ of the net annual increment in forestry biomass is available for wood supply [39]. However, a sustainable forest management is crucial in maintaining their potential and their ecosystem services.

In this perspective, the extensive use of biomass, both in the residential sector and for electricity production in power plants, is considered as one of the alternatives to fossil fuel and is a win-win option in terms of environmental and socioeconomic aspects.

The attention of the scientific community and policy towards the use of wood as a heating source is steadily increasing. However, if not managed in a sustainable way, the use of wood can cause direct impacts from extraction and distribution (such as excessive harvesting leading to clearance, soil erosion, loss of forest area, and loss of biodiversity in plantations and secondary forest) and disturbance to material cycles (such as the reduction of the carbon storage function). Moreover, while the contribution of this source of energy can be considered carbon neutral, its use, especially in low-tech plants, appears to contribute significantly to air quality (especially due to PM emissions) both in urban and in rural areas. Incomplete combustion can produce pyrogenic emission of trace gases and aerosol precursors that influence atmospheric chemistry and radiative balance. The high content of carbonaceous components makes these kind of emissions very interesting from the climate change point of view due to the emergence of elemental carbon which is the primary responsible of light absorption and, as a consequence, of the direct radiative effect of aerosol on climate [40]. Moreover, biomass burning also releases organic compounds which significantly absorb the high-frequency fraction of the visible and UV radiation.

Therefore, it is necessary that the choice to promote wood use as a renewable energy source is made taking into account sustainability in a broader sense, considering, for instance, the availability of resources at a local scale 
and the environmental impacts throughout the whole supply chain, in a life cycle perspective [41].

\section{The Po Valley hot spot in Europe}

Po Valley (Figure 2) is a major geographical feature in Italy. It extends approximately $650 \mathrm{~km}$ in an east-west direction, with an area of $46 \mathrm{~km}^{2}$. In Po Valley, the climate is typically continental although mitigated by the influence of the Adriatic Sea and by the shielding of the Alps. The atmospheric circulation is often stagnant in Po Valley especially during wintertime, when frequent thermal inversions at low altitude, low mixing layer heights and prolonged foggy or hazy periods occur. The wind speed is generally low (the average wind speed is $1.5 \mathrm{~ms}^{-1}$ during winter and $1.8 \mathrm{~ms}^{-1}$ during summer), and a high rainfall rate is generally registered during the autumn and winter seasons. This condition of atmospheric stability leads to the accumulation of pollutants [42]. In addition, Po Valley is one of the most industrialized areas of the country. Therefore, this area is often considered one of the largest pollution 'hot spots' in Europe [43] and is a representative case for air pollution policies [44].

In Lombardy, the biggest region in Po Valley, about $16 \%$ of households have a wood burning appliance, and generally, it is an old and inefficient system; in fact, only $10 \%$ of households are equipped with modern combustion systems (automatic pellet or chip stoves, innovative log wood stoves) [45].

In Po Valley, the distribution of pollutants tends to be uniform, losing the dependence on the sources. For instance, in the metropolitan area of Milan, $10 \%$ of winter
$\mathrm{PM}_{10}$ concentration [46] and a large part of toxic pollutants (i.e., polycyclic aromatic hydrocarbons (PAH)) appear as linked to household wood combustion [47], despite of the fact that only $3 \%$ of households use it for domestic heating. In Turin (main city of the Piedmont region which has 908,853 inhabitants), which is $120 \mathrm{~km}$ from Milan, the situation is very similar. About $15 \%$ of $\mathrm{PM}_{10}$ and $70 \%$ of winter concentrations of benzo(a)pyrene - the most toxic PAH - were estimated to be caused by wood burning [48].

Therefore, policy responses to air pollution cannot be addressed only to one source (i.e., to one single driver, referring to the DPSIR framework), but they need to take into consideration all the aspects of this environmental problem. Moreover, since the emission sources are local, but the effects spread into a wider area, effective policies from decision makers need to be referred to the entire Po Valley.

Two different and contrasting issues should be taken into account in order to discuss the wood combustion policy in Po Valley:

- Stimulating the market in small-scale wood combustion can contribute to the development of renewable energy (RE) as required by the national target for RE.

- Increasing wood combustion could lead to a worsening of air pollution which is currently frequently beyond the law limits.

So far, despite the specific local condition demands to act with integrated assessment and policies throughout Po Valley, frequently, the regional authorities (Lombardy,

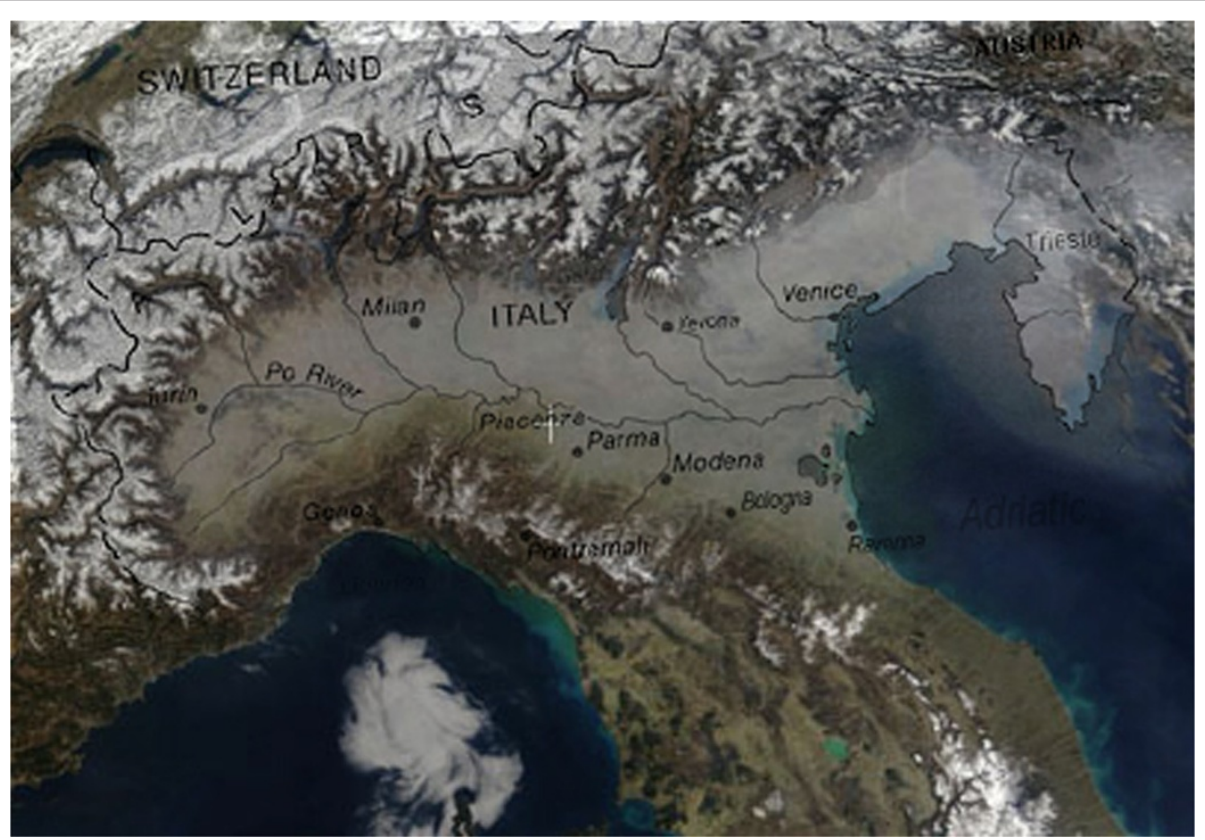

Figure 2 Image of Po Valley showing air pollutant accumulation. 
Piedmont, and Veneto) have addressed the problem in a different way.

A first bylaw of the Lombardy region (DGR 7635/08) has prescribed that in urban areas with high population density and in municipality sites less than $300 \mathrm{~m}$ above sea level in height - and where there are other heat systems over the stove - there is the prohibition to use firewood in the winter for space heating of buildings in open fireplaces, chimneys closed, stoves, and any other type of device which does not ensure an adequate energy efficiency $(\geq 63 \%)$ and low emissions of carbon monoxide $(\leq 0,5 \%=5,000 \mathrm{ppm})$. It is also prohibited Combustion of wood outdoors is also prohibited.

This initiative has been isolated; none thereof were undertaken in Po Valley. In order to harmonize the actions aimed at defining a plan for air quality improvement, local authorities, on the basis of an agreement signed in October 2005 and specified operationally in February 2007, established a permanent technical board for the activities' coordination for the management of issues concerning air quality improvement. In Table 1, the actions taken by the various local governments are summarized [49].

Nowadays, in Italy, the emission limits for medium- and large-sized appliances and biomass fuel characteristics are defined by law (Leg. 152/2006). Contrarily, emission limits for biomass combustion are not currently applicable with power less than $35 \mathrm{~kW}$, i.e., for small household appliances.

The Lombardy region has intervened independently, defining a regulation to reduce the environmental impact of wood combustion, with an integrated approach having the following aims:

- To restrict the use of older and more pollutant appliances;

- To promote the renewal of equipment in favor of the most efficient and less emission;

- To regulate the installation and maintenance of household appliances;

- To spread the use of 'Best Practices' for better combustion of wood in household appliances.
Guidelines for wood burning arising from research findings

A literature review about forestry operations within wood chains highlights that environmental impacts can be generated along the whole chain. Indeed, they consist not only of the removal of woody biomass (i.e., cutting of trees), but also, among others, of the impacts generated by the use of forestry machinery and related use of fossil fuels. In addition, they depend also on the techniques used for the extraction of wood, the manner in which the cut is made, including the choice of machines that are used to perform the felling and handling of stems, as well as the temporal and spatial planning of silvicultural treatments of forests. Moreover, when the wood is used for energy production, the use phase can generate relevant impacts in term of air pollution emissions, depending on the type of burning appliance used and the burning conditions (i.e., on the user knowledge about best practices) [50].

Therefore, to ensure sustainability of the chain, all of these issues should be taken into account and guidelines for sustainable use of wood fuel should regard all phases of the supply chain, in a life cycle perspective, from the quantification of the biomass available with reference to the carrying capacity of forest ecosystems, to the choice of the burning appliances, and their operational mode.

In the following paragraphs, the wood energy supply chain is taken as an example to explain what should be the actions to be undertaken in order to make the best use of scientific research findings as a support to decision making in all stages of the supply chain. Table 2 summarizes the most important guidelines.

Forest management Sustainability assessment of forest biomass use should be based firstly on the evaluation of the carrying capacity (CC) of the forest ecosystem, to ensure renewability of the system itself through time [12]. $\mathrm{CC}$ of a system is considered as the limit of exploitation of a resource that does not affect the functions of the system itself. Due to spatial variability of forest features, sitespecific aspects affecting sustainability of resource use (e.g., the local accessibility of raw materials and the distance from the processing plant to the delivery point) have

Table 1 Summary of actions taken by the local authorities in Po Valley

\begin{tabular}{|c|c|}
\hline & Actions \\
\hline $\begin{array}{l}\text { Friuli Venezia } \\
\text { Giulia }\end{array}$ & $\begin{array}{l}\text { After the third day when the air quality limits are exceeded, replace the residential combustion of wood (if possible), with the } \\
\text { exception of pellets, with other forms of combustion or heating }\end{array}$ \\
\hline \multirow{3}{*}{$\begin{array}{l}\text { Bolzano } \\
\text { province }\end{array}$} & Combustion system > 35 kW required annual emission check \\
\hline & Combustion system $<35 \mathrm{~kW}$ required cleaning of flue three times year \\
\hline & Realization of district heating systems fueled by wood has incentives \\
\hline Trento province & Device installations for reducing emissions small existing systems have incentives \\
\hline $\begin{array}{l}\text { Lombardy } \\
\text { region }\end{array}$ & $\begin{array}{l}\text { Limiting the use of wood-burning plants with low yields in urban areas with high population density and municipality sites of less } \\
\text { than } 300 \mathrm{~m} \text { above sea level in height }\end{array}$ \\
\hline Piemonte region & Combustion system $>35 \mathrm{~kW}$ of emission limits is more stringent than the national law \\
\hline
\end{tabular}


to be considered. In the literature, evaluation of biomass availability is commonly recognized as one of the first steps to plan the installation of combustion plants [51-54], but usually, there is a lack of comprehensive assessment of $\mathrm{CC}$, which should entail site-specific environmental, operational, and technical issues that may limit the amount of biomass that can be sustainably harvested. Therefore, the best practices in the stage of forestry operation should be to follow sustainable forestry criteria (e.g., selective cutting instead of clear-cutting) and to define the maximum amount of withdrawable biomass according to the sitespecific carrying capacity of the forest ecosystem.

Forestry operations Several studies, mainly using life cycle assessment methodology, have been carried out in order to assess the environmental impact of forestry operations (e.g., [55-59]). Michelsen et al. [59] found that extraction operations and transports are responsible for $85 \%$ of the total environmental impacts of a woodtimber supply chain.
From a life cycle perspective, fuel consumption and related emissions proved to be the main source of impacts along the chain; hence, it is very important to prioritize the operational mode able to minimize the hours necessary to perform each operation. It was also found that each technology should be chosen according to the morphology and characteristics of the area investigated, and no one method can be assumed as the most suitable for all conditions. For instance, traditional mechanization with cable-logging post-delimbing was found to be the best option for Lombardy areas [60], but through sensitivity analyses, it was shown that advanced mechanization if utilized at the top productivity or equipped with diesel particulate filters or selective catalytic reduction systems could be the best solution in other cases [61]. The reason stands in advanced mechanization high productivity that allows several operations to be performed in a short time. Therefore, it is important to choose the most efficient harvesting system in site-specific conditions, in order to reduce the amount of working hours needed, i.e., the fuel consumption.

Table 2 Critical issues, guidelines for sustainable use of wood as energy source, and stakeholders to be involved

\begin{tabular}{|c|c|c|c|c|}
\hline $\begin{array}{l}\text { Elements of } \\
\text { the supply } \\
\text { chain }\end{array}$ & $\begin{array}{l}\text { Critical issues (as result of scientific } \\
\text { research) }\end{array}$ & Guidelines & $\begin{array}{l}\text { Target } \\
\text { audience }\end{array}$ & Possible mediator \\
\hline \multirow[t]{3}{*}{$\begin{array}{l}\text { Forestry } \\
\text { operations }\end{array}$} & $\begin{array}{l}\text { Amount of withdrawable woody } \\
\text { biomass }\end{array}$ & $\begin{array}{l}\text { Define the amount of available biomass } \\
\text { according to the carrying capacity of the } \\
\text { forest ecosystem }\end{array}$ & \multirow{3}{*}{$\begin{array}{l}\text { Forest } \\
\text { managers } \\
\text { and wood } \\
\text { cutters }\end{array}$} & \multirow[t]{3}{*}{$\begin{array}{l}\text { Forestry consortium } \\
\text { (including forest planners, } \\
\text { foresters, and forestry firms) }\end{array}$} \\
\hline & $\begin{array}{l}\text { Fossil fuel consumption (chainsaws and } \\
\text { other machinery) }\end{array}$ & $\begin{array}{l}\text { Choose the most efficient harvesting system } \\
\text { (e.g., debranching before cable logging helps } \\
\text { to reduce fuel consumption) }\end{array}$ & & \\
\hline & $\begin{array}{l}\text { Impacts on the forest ecosystems (e.g., } \\
\text { oil emission, clearance, soil erosion) }\end{array}$ & $\begin{array}{l}\text { Follow sustainable forestry criteria (e.g., } \\
\text { selective cutting instead of clear-cutting) }\end{array}$ & & \\
\hline \multirow{3}{*}{$\begin{array}{l}\text { Choice of } \\
\text { wood- } \\
\text { burning } \\
\text { appliances }\end{array}$} & $\begin{array}{l}\text { Inefficient combustion leads to higher } \\
\text { emission }\end{array}$ & Develop new and more efficient technologies & \multirow[t]{3}{*}{$\begin{array}{l}\text { Boilers' } \\
\text { producers }\end{array}$} & \multirow[t]{3}{*}{ Producers' association } \\
\hline & PM air emissions & Install appropriate emission control devices & & \\
\hline & $\begin{array}{l}\text { Oversizing can lead to a request for } \\
\text { more biomass than what is needed and } \\
\text { what is available in the area }\end{array}$ & $\begin{array}{l}\text { Prefer distributed generation instead of big } \\
\text { plants }\end{array}$ & & \\
\hline \multirow[t]{9}{*}{$\begin{array}{l}\text { Wood } \\
\text { burning }\end{array}$} & $\begin{array}{l}\text { Inefficient combustion leads to higher } \\
\text { emission }\end{array}$ & $\begin{array}{l}\text { Prefer chip boilers, pellet, and wood modern } \\
\text { stoves instead of open fireplaces. }\end{array}$ & Users & $\begin{array}{l}\text { Citizens'/consumers' } \\
\text { association }\end{array}$ \\
\hline & Pollutant air emissions & $\begin{array}{l}\text { Substitute old appliances with new ones } \\
\text { (safer and more efficient) }\end{array}$ & & \\
\hline & \multirow{2}{*}{$\begin{array}{l}\text { Carelessness of the log wood-burning } \\
\text { appliance causes high emission } \\
\text { pollutants }\end{array}$} & Frequent ash removal & & \\
\hline & & Routine maintenance of the flue & & \\
\hline & $\begin{array}{l}\text { Correct use of stoves leads to a } \\
\text { reduction in emissions }\end{array}$ & Proper firing modes & & \\
\hline & \multirow{3}{*}{$\begin{array}{l}\text { Pollutant emission also depends on the } \\
\text { fuel type }\end{array}$} & Use forest wood instead of wood waste & & \\
\hline & & Burn only dried wood (R.H. <50) & & \\
\hline & & $\begin{array}{l}\text { Prefer hardwood and low-resin wood instead } \\
\text { of softwood }\end{array}$ & & \\
\hline & $\begin{array}{l}\text { Wood log/chip/pellet transport implies } \\
\text { fossil fuel consumption }\end{array}$ & Buy wood from a short supply chain & & \\
\hline
\end{tabular}


Burning appliances In general, old-type wood boilers cause considerably higher emissions than modern wood and pellet boilers. The mass concentration of particles was 180 times larger in the worst old-type case (a water-cooled wood boiler without heat storage tank) compared to the best modern case (wood pellets) [62].

One of the key innovations to reduce emissions in boiler design is the use of boilers designed for staged combustion and gasification. Besides, process monitors (such as those that monitor temperature, oxygen, and carbon monoxide levels) can be installed and used with predefined schemes to minimize emissions and to optimize efficiency as well as to ensure optimum operating parameters. These system types allow automatic adjustments of air-to-fuel ratios; redistribution of combustion air between the primary, secondary, and (possibly) tertiary combustion zones; and fuel feed rates for stable combustion [63].

In a recent work, Nussbaumer [63] summarizes the currently available technologies that are applied to flue gas after completion of the combustion process to reduce emissions of particulate matter from wood combustion. Nussbaumer concluded that 'There are several technically feasible combustion control options available for existing small- and medium-sized boiler[s] that will reduce emissions. In order to reach these emission levels, boiler operations must be optimized, and advanced emission control devices, such as fabric filters, will need to be installed. Based upon discussions with air quality regulators, it is likely that the advanced combustion control devices would be deemed economically feasible as well".

Wood burning Pellets or wood chip combustion guarantees emission levels lower than the logs' wood combustion, and this is mainly due to the following factors:

- Small size of the fuel and its porosity favor the mixture with combustion air; therefore, there is more efficient combustion.

- Homogeneity of the fuel (size, humidity) favors the identification of best combustion conditions.

- Stoves/boilers are equipped with automatic systems for the control of fuel combustion air ratio.

These conditions do not occur during log wood combustion, especially in small household systems, where the discretion of the user (e.g., frequency of stove maintenance operations and choice of wood type) is very high. Therefore, it is important to promote educational activities in order to convey knowledge about the best practices of burning wood. Unlike the wide body of literature available about the comparison of emissions from several types of boilers, there are only few scientific publications about the best practices in using boilers, i.e., in emission dependence from using conditions; however, the technical knowledge developed by practitioners (e.g., the Italian Agroforestry Energy Association (AIEL) [64-66]) can be helpful in identifying the guidelines to be delivered to the final users:

- Concerning boilers and stove maintenance, frequent ash removal and routine maintenance can ensure optimum performance and can reduce ash entrainment, which increases PM emissions.

o Increasing humidity of the fuel causes the increase of pollutant emission, so it is advisable to use wood with moisture content lower than $40 \%$.

o Only wood from forest must be used, avoiding the use of wood waste (e.g., from packaging and industry residues) that has been chemically treated and may result in the emission of pollutants during combustion. o Some types of wood, e.g., hardwood or wood with low resin content, provide better combustion and lower emissions.

o Proper firing modes can reduce the emission level: it is advisable to use lighter devices and turning on the pile of wood from the top (like a candle) rather than from below because this ensures cleaner combustion.

\section{Conclusions}

It is widely demonstrated that the synergies between those who produce information and those who should use it for informed decision making are still barely explored. The article discussed this issue taking as reference the case of wood as a renewable energy source, focusing on one of the European hot spots for air pollution, Po Valley in Northern Italy. It proved to be an interesting case, especially because of the ambiguity between the positive and the negative aspects of wood burning, which, if not adequately integrated by information about the specific conditions that influence pollution levels, can lead to opposite political decisions about the use of wood in local energy plans.

Some general conclusions can be drawn by the case study, which can be valid also for a wider range of environmental issues: (1) the scientific community should be conscious of the importance of putting the research findings in a wider picture, trying to translate their findings into practical information to support decisions (e.g., 'wood burning can be a source of pollutants if not made properly; [there are] guidelines to be [followed] in order to make sustainable use of wood resource...'); (2) it is important to establish a more permanent relationship between researchers and decision makers in order to promote a mutual exchange and feedback, aimed at identifying the most suitable solutions in the specific condition under study; (3) in order to promote this relationship, a shift in the attitude of the scientific community is needed, starting from the acknowledgment of communication (not only as scientific publications) as one of the task of researchers 
and the inclusion of communication skills in scientific education.

In addition, it is interesting to note that when scientific literature about best practice is not available (e.g., in the case of wood burning practices), the knowledge may come from other sources, as it is for AIEL. Moreover, associations and existing networks can also be very useful as intermediaries for translating the knowledge into a more usable format and to convey information to the final targets identified (e.g., policy makers, firms, and final users).

\section{Methods}

Science-policy interface is increasingly considered a key step for developing robust and effective policies. In order to explore the interface process, after a literature review of the 'State of the art in the relationship between science and decision making, the main barriers in the relationship between science and decision making have been analyzed. As example, the use of wood resources as renewable energy source has been selected. This choice is due to the fact that the use of wood is highly debated for its possible benefits and drawbacks in term of environmental sustainability, which strongly depend on the way in which wood is managed along the whole supply chain. Hence, the wood energy supply chain is taken as an example to explain what should be the actions to be undertaken in order to make the best use of scientific research findings as a support to decision making in all stages of the supply chain. A real case has been selected in order to highlight how to transform research finding in operational guidelines, systematizing existing knowledge in different research areas and harmonizing input for decision support or helping identifying trade-off suitable for decision making. The case study location (Po Valley, in Northern Italy) has been taken as reference because it is one of the air pollution hot spots in Europe.

\section{Competing interests}

The authors declare that they have no competing interests.

\section{Authors' contribution}

The study was designed by AP and VC. VC defined the structure of the paper, edited the text, and wrote part of 'State of the art in the relationship between science and decision making' and 'Main barriers in the relationship between science and decision making' sections, part of 'Guidelines for wood burning arising from research findings', 'Forest management', and 'Forestry operations' sections, and the 'Conclusions' section. AP wrote 'The Po Valley hot spot in Europe' subsection and part of 'Burning appliances' and 'Wood burning' subsections. SS wrote part of the 'Background' section and part of 'The case of renewable energy from woody biomass' section and revised the text. All authors read and approved the final manuscript.

\section{Authors' information}

VC has a PhD in Environmental Science and Sustainability and has been focusing her research activity on sustainability assessment through the use of sustainability indicators and life cycle assessment methodology. During her research, she worked with policy makers and industries in order to find better ways to convey research results into decision making in all levels. AP has a PhD in Environmental and Analytical Chemistry. His scientific attention focuses on the investigation of air pollution sources. On this topic, he has recently published results of wood combustion impact on the air quality of Po Valley (Northern Italy). He collaborated with several initiatives for the dissemination of best practices in wood burning. SS has a PhD in Applied Ecology and Ecotoxicology and has been focusing her research activities on sustainability science development in a trans-disciplinary fashion. After 10 year at the university in the research group on sustainability science at the Department of Earth and Environmental Science, she has been working for 3 years at the Joint Research Centre of the European Commission. During this latest experience, she developed a framework and meta-framework for sustainability assessment, in light of strengthening science-policy interface.

\section{Author details}

${ }^{1}$ Department of Earth and Environmental Science, University of Milano-Bicocca, Piazza della Scienza 1, Milan 20126, Italy. ²European Commission, Joint Research Centre Institute for Environment and Sustainability, Sustainability Assessment Unit, Via Enrico Fermi 2749; T.P. 270, Ispra (VA) 21027, Italy.

Received: 18 March 2013 Accepted: 1 August 2013

Published: 15 August 2013

\section{References}

1. UNECE: Convention on Access to Information, Public Participation in Decision-making and Access to Justice in Environmental Matters. Geneva: UNECE; 1998.

2. Hartley $\mathrm{N}$, Wood C: Public participation in environmental impact assessment-implementing the Aarhus Convention. Environ impact asses 2005, 25:319-340.

3. Sala S, Farioli F, Zamagni A: Progress in sustainability science: lessons learnt from current methodologies for sustainability assessment: Part 1. Int J Life Cycle Asses 2012. doi:10.1007/s11367-012-0508-6.

4. Storni A, Castellani V, Sala S: Working with stakeholders for a successful research on sustainable development. In Sustainable Development at Universities: New Horizons. Volume 34. Edited by Leal Filho W. Frankfurt: Peter Lang; 2012:994.

5. Clark R: Using Research to Inform Policy: the Role of Interpretation. Final Report. Swindon: Environment Research Funders' Forum; 2007.

6. Scott K: Discussions and lessons learned. In A Literature Review on Sustainable Lifestyles and Recommendations for Further Research. Stockolm: Stockholm Environment Institute; 2009:42.

7. Hargreaves T: Practice-ing behaviour change: applying social practice theory to pro-environmental behaviour change. J Consum Cult 2011, 11:79-99.

8. Schrader $U$, Thøgersen J: Putting sustainable consumption into practice. J Consum Policy 2011, 34:3-8.

9. Vanpeperstraete B, Duyck S, Bhandari MP, Brizga J, Rijnhout L, Lorek S, Castro AP, Chang CT, Daly H, Didham RJ, Ferraro G, Greenfield O, Khosla A, von Weizsäcker EU, Lode B, Miles S, Pacini H, Silveira S, Perch L, Rijnsburger J, Sanwal M, Savarala S, Scherr SJ, Seetharam KE, Adeeb AMM, Shepherd D, Smith A, Ulatowska L, Vincent A, John W: What do you think should be the two or three highest priority political outcomes of the United Nations conference on sustainable development (Rio +20$)$, scheduled for Rio de Janeiro in June 2012? Natural Resources Forum 2011, 35:334-342.

10. Haas P: When does power listen to truth? A constructivist approach to the policy process. J Eur Public Policy 2004, 11:569-592.

11. Smeets E, Weterings R: Environmental Indicators: Typology and Overview. Copenhagen: European Environment Agency; 1999.

12. Ausubel JH: Can technology spare the earth? American Scientist 1996 84:166-178.

13. Hawken P, Lovins A, Lovins H: Natural Capitalism: Creating the Next Industrial Revolution. New York: Little, Brown and Company; 1999.

14. Collins HM: Stages in the empirical programme of relativism. Soc Stud Sci 1981, 11:3-10.

15. Tester K: Animals and Society. New York: Routledge; 1991.

16. Woolgar S: Science: The Very Idea! London: Tavistock; 1988

17. Collins H: We cannot live by scepticism alone. Nature 2009, 458:30.

18. Dupré J, Griffiths PE: Let's not reignite an unproductive controversy. Nature 2009, 458:702.

19. Hulme M: What does applying "scientific values" mean in reality? Nature 2009, 458:702

20. Dean C: Am I Making Myself Clear? A Scientist's Guide to Talking to the Public. Cambridge: Harvard University Press; 2009. 
21. Biermann F, Betsill MM, Gupta J, Kanie N, Lebel L, Liverman D, Schroeder H, Siebenhüner B, Zondervan R: Earth system governance: a research framework. Int Environ Agreements: Politics, Law and Economics 2010, 10:277-298.

22. Behringer J, Buerki R, Fuhrer J: Participatory integrated assessment of adaptation to climate change in Alpine tourism and mountain agriculture. Integ Asses 2000, 1:331-338.

23. York R, Clark B: Critical materialism: science, technology, and environmental sustainability. Sociol Ing 2010, 80:475-499.

24. Turnhout $\mathrm{E}$, Hisschemoller M, Eijsackers H: Ecological indicators: between the two fires of science and policy. Ecol Indic 2007, 7:215-228.

25. Vareman N, Persson J: Why separate risk assessors and risk managers? Further external values affecting the risk assessor qua risk assessor. J Risk Res 2010, 13:687-700.

26. Mayo D: Sociological versus metascientific views of risk assessment. In Acceptable Evidence: Science and Values in Risk Management. Edited by Mayo DG, Hollander RD. New York: Oxford University Press; 1991:249-280.

27. Castellani V: Development of methodologies and indicators to assess sustainability in tourism and agriculture. In PhD dissertation. University of Milano-Bicocca, Department of Earth and Environmental Sciences; 2010.

28. Reid WV, Chen D, Goldfarb L, Hackmann H, Lee YT, Mokhele K, Ostrom E, Raivio K, Rockström J, Schellnhuber HJ, Whyte A: Earth system science for global sustainability: grand challenges. Science 2010, 330:916-917.

29. Holmes J, Clark R: Enhancing the use of science in environmental policy-making and regulation. Environ Sci Policy 2008, 11:702-711.

30. Scott A, Holmes J, Steyn G, Wickham S, Murlis J: Science meets policy 2005: next steps for an effective science-policy interface. In Report of London Conference held as Part of the UK's Presidency of the European Union, 23-25 November 2005. London: Department for Environment, Food and Rural Affairs; 2006:24

31. Bielak AT, Holmes J, Savgård J, Schaefer K: A Comparison of European and North American Approaches to the Management and Communication of Environmental Research. Fredericton: Environment Canada; 2009.

32. Swart R, Raskin P, Robinson J: The problem of the future: sustainability science and scenario analysis. Glob Environ Chang 2004, 14:137-146.

33. Wardekker JA, Van der Sluijs JP, Janssen PHM, Kloprogge P, Petersen AC: Uncertainty communication in environmental assessments: views from the Dutch science-policy interface. Environ Sci Policy 2008, 11:627-641.

34. Perrings C, Duraiappah A, Larigauderie A, Mooney H: Ecology: the biodiversity and ecosystem services science-policy interface. Science (New York, NY) 2011, 331:1139-1140.

35. Sutherland WJ, Fleishman E, Mascia MB, Pretty J, Rudd MA: Methods for collaboratively identifying research priorities and emerging issues in science and policy. Methods Ecol Evol 2011, 2:238-247.

36. European Commission: A Resource-efficient Europe - Flagship Initiative Under the Europe 2020 Strategy. Brussels: European Commission; 2011.

37. European Commission: Biomass Action Plan. Brussels: European Commission; 2005.

38. European Commission: Innovating for Sustainable Growth: A Bioeconomy for Europe. Brussels: European Commission; 2012.

39. Food and Agriculture Organization of the United Nations: Global Forest Resources Assessment 2010. Rome: FAO; 2010.

40. Andreae $\mathrm{MO}$, Gelencs $\mathrm{A}, \mathrm{Box} \mathrm{PO}$, Veszpr H: Black carbon or brown carbon? The nature of light-absorbing carbonaceous aerosols. Atmos. Chem. Phys 2006, 6:3131-3148.

41. Sala S, Castellani V: Technology sustainability assessment to support decision making on energy production at local scale. Int J Sust Dev Plan 2011, 6:251-267.

42. Vecchi R, Marcazzan G, Valli G, Ceriani M, Antoniazzi C: The role of atmospheric dispersion in the seasonal variation of PM1 and PM2.5 concentration and composition in the urban area of Milan (Italy). Atmos Environ 2004, 38:4437-4446.

43. Vecchi R, Bernardoni V, Fermo P, Lucarelli F, Mazzei F, Nava S, Prati P Piazzalunga A, Valli G: 4-Hours resolution data to study PM10 in a "hot spot" area in Europe. Environ Monit Assess 2009, 154:283-300.

44. Carnevale C, Finzi G, Pisoni E, Volta M, Guariso G, Gianfreda R, Maffeis G, Thunis P, White L, Triacchini G: An integrated assessment tool to define effective air quality policies at regional scale. Environ Model Software 2012, 38:306-315.

45. Pastorello C, Caserini S, Galante S, Dilara P, Galletti F: Importance of activity data for improving the residential wood combustion emission inventory at regional level. Atmospheric Environment 2011, 45:2869-2876.
46. Piazzalunga A, Belis C, Bernardoni V, Cazzuli O, Fermo P, Valli G, Vecchi R: Estimates of wood burning contribution to PM by the macro-tracer method using tailored emission factors. Atmos Environ 2011, 45:6642-6649.

47. Belis CA, Cancelinha J, Duane M, Forcina V, Pedroni V, Passarella R, Tanet G, Douglas K, Piazzalunga A, Bolzacchini E, Sangiorgi G, Perrone M-G, Ferrero L, Fermo P, Larsen BR: Sources for PM air pollution in the Po Plain, Italy: I. Critical comparison of methods for estimating biomass burning contributions to benzo(a)pyrene. Atmos Environ 2011, 45:7266-7275.

48. Piazzalunga A, Anzano M, Collina E, Lasagni M: Contribution of wood combustion to $\mathrm{PAH}$ and PCDD/F concentrations in two urban sites in Northern Italy. J Aerosol Sci 2013, 56:30-40.

49. Mussinatto A: Le emissioni dalla combustione della legna in piccoli impianti domestici e la qualità dell'aria. Le politiche a scala di bacino padano. Conference speech, 23 May 2011; Milan. [http://www.inemar.eu/xwiki/bin/download/ InemarWiki/ConvegnoLegna/Mussinatto230511.pdf] Accessed August 2013.

50. Cespi D, Passarini F, Ciacci L, Vassura I, Castellani V, Collina E, Piazzalunga A, Morselli L: Heating systems LCA: comparison of biomass-based appliances. Int J LCA 2013. doi:10.1007/s11367-013-0611-3.

51. Viana H, Cohen WB, Lopes D, Aranha J: Assessment of forest biomass for use as energy. GIS-based analysis of geographical availability and locations of wood-fired power plants in Portugal. Appl Energy 2010, 87:2551-2560.

52. Yoshioka T, Sakurai R, Aruga K, Sakai H, Kobayashi H, Inoue K: A GIS-based analysis on the relationship between the annual available amount and the procurement cost of forest biomass in a mountainous region in Japan. Biomass Bioenergy 2011, 35:4530-4537.

53. Alfonso D, Perpiñá C, Pérez-Navarro A, Peñalvo E, Vargas C, Cárdenas R: Methodology for optimization of distributed biomass resources evaluation, management and final energy use. Biomass Bioenergy 2009, 33:1070-1079.

54. Voivontas D, Assimacopoulos D, Koukios EG: Assessment of biomass potential for power production: a GIS based method. Biomass and Bioenergy 2001, 20:101-112.

55. Aldentun $Y$ : Life cycle inventory of forest seedling production-from seed to regeneration site. J Cleaner Prod 2002, 10:47-55.

56. Berg S, Lindholm E-L: Energy use and environmental impacts of forest operations in Sweden. J Cleaner Prod 2005, 13:33-42.

57. González-García S, Berg S, Moreira MT, Feijoo G: Evaluation of forest operations in Spanish eucalypt plantations under a life cycle assessment perspective. Scand J Forest Res 2009, 24:160-172.

58. González-García S, Berg S, Feijoo G, Moreira MT: Environmental impacts of forest production and supply of pulpwood: Spanish and Swedish case studies. Int J Life Cycle Assess 2009, 14:340-353.

59. Michelsen O, Solli C, Strømman AH: Environmental impact and added value in forestry operations in Norway. $J$ Ind Ecol 2008, 12:69-81.

60. Marra M, Castellani V, Mirabella N, Sala S, Negri M, Guercini S: Technological characteristics and sustainability assessment of short forestry-wood chain for Alpine hardwood furniture. In Proceedings of the 3rd International Scientific Conference on Hardwood Processing (ISCHP32011) I: Peer Reviewed Contributions. Edited by Buehlmann U. Blacksburg: ISCHP; 2011:301.

61. Castellani V, Martire S, Mirabella N, Sala S: La filiera corta bosco mobile. In Manuale per la valorizzazione del legname di Acero, Faggio e Frassino Progetto BOSCO-MOBILE. Edited by Zucchi C. Milan: Regione Lombardia; 2012:108.

62. Johansson LS, Leckner B, Gustavsson L, Cooper D, Tullin C, Potter A: Emission characteristics of modern and old-type residential boilers fired with wood logs and wood pellets. Atmos Environ 2004, 38:4183-4195.

63. Nussbaumer T: Overview on technologies for biomass combustion and emission levels of particulate matter [http://citepaax.alias.domicile.fr/ forums/egtei/Nussbaumer_EGTEl-Report final.pdf]

64. Francescato V, Antonini E: La Combustione Del Legno. Fattori Di Emissione e Quadro Normativo. Legnaro: Veneto Agricoltura - Azienda regionale per i settori agricolo, forestale e agroalimentare; 2010:34.

65. Francescato V: La combustione del legno. Tecnologie e impatti. Conference speech, 21 October 2011, Città di Castello (PG), Italy [http://www.utopieconcrete.it/download/fiera\%202011/Francescato.pdf] Accessed August 2013

66. Francescato V, Antonini E, Zuccoli Bergomi L: Wood Fuels Handbook. Legnaro: Italian Agroforestry Energy Association; 2008:83.

doi:10.1186/2190-4715-25-22

Cite this article as: Castellani et al.: Research findings and decision making: the case of renewable energy. Environmental Sciences Europe $201325: 22$ 